\title{
$\alpha$-lipoic acid exerts neuroprotective effects on neuronal cells by upregulating the expression of PCNA via the P53 pathway in neurodegenerative conditions
}

\author{
DA-WEI LI ${ }^{1 *}$, YING-DI WANG ${ }^{2 *}$, SHI-YAO ZHOU ${ }^{3}$ and WEN-PING SUN ${ }^{1}$ \\ ${ }^{1}$ Department of Neurology, Affiliated Hospital of Beihua University, Jilin, Jilin 132011; ${ }^{2}$ Department of Urinary Surgery, \\ Tumor Hospital of Jilin; ${ }^{3}$ Department of Clinical Medicine, Jilin University, Changchun, Jilin 130021, P.R. China
}

Received August 19, 2015; Accepted August 15, 2016

DOI: $10.3892 / \mathrm{mmr} .2016 .5754$

\begin{abstract}
Oxidative stress appears to be a central event responsiblefor the degeneration of dopaminergic neuronsinParkinson's disease (PD). 1-methyl-4-phenyl-1,2,3,6-tetrahydropyridine or its toxic metabolite 1-methyl-4-phenylpyridinium $\left(\mathrm{MPP}^{+}\right)$ are classical widely-used pharmacological and toxic agents to model PD; they cause the production of reactive oxygen species by inhibiting mitochondrial complex I, leading to DNA oxidative damage and subsequent neuronal death. Previous findings have suggested that proliferating cell nuclear antigen (PCNA), a critical regulatory protein for DNA repair, is involved in dopaminergic neuron damage in the $\mathrm{MPP}^{+}$-induced PD model. The naturally occurring dithiol compound, $\alpha$-lipoic acid (ALA) has been reported to provide neuroprotection in in vitro models of $\mathrm{PD}$. The molecular mechanism by which ALA reduces neuronal death in PD remains to be fully elucidated. The present study aimed to analyze the ability of ALA to protect neuronal $\mathrm{PC} 12$ cells from the toxicity induced by $\mathrm{MPP}^{+}$, and the molecular mechanism underlying these actions using MTT and lactate dehydrogenase cytotoxicity assays, Hoechst 33258 staining and western blot analysis. The results demonstrated that ALA efficiently increased the production of PCNA in $\mathrm{MPP}^{+}$-treated PC12 cells. Accordingly, ALA treatment attenuated $\mathrm{MPP}^{+}$-induced toxicity in the $\mathrm{PC} 12$ cells, and
\end{abstract}

Correspondence to: Professor Wen-Ping Sun, Department of Neurology, Affiliated Hospital of Beihua University, 12 Jiefang Road, Jilin, Jilin 132011, P.R. China

E-mail: sunwpjilin@163.com

*Contributed equally

Abbreviations: $\mathrm{PD}$, Parkinson's disease; SNpc, substantia nigra pars compacta; $\mathrm{MPP}^{+}$, 1-methyl-4-phenylpyridinium; MPTP, 1-methyl-4-phenyl-1,2,3,6-tetrahydropy-ridine; PCNA, proliferating cell nuclear antigen; ALA, $\alpha$-lipoic acid

Key words: Parkinson's disease, 1-methyl-4-phenylpyridinium, $\alpha$-lipoic acid, neuroprotection, proliferating cell nuclear antigen, P53 reduced cell apoptosis. The increase in the expression levels of PCNA by ALA in the $\mathrm{MPP}^{+}$-treated PC12 cells appeared to be mediated by repression of the 553 protein, as the expression of p53 was increased by $\mathrm{MPP}^{+}$-treatment and reduced by ALA. Taken together, these results indicated that ALA protected dopaminergic neurons against $\mathrm{MPP}^{+}$-induced neurotoxicity through its ability to upregulate the DNA repair protein, PCNA, via the P53 pathway.

\section{Introduction}

Parkinson's disease (PD) is a movement disorder characterized by motor and behavioral disturbances, caused by the gradually progressive and selective degeneration of dopaminergic neurons in the substantia nigra pars compacta (SNpc) (1).

The pathogenesis of PD remains to be fully elucidated, however, multiple studies have linked oxidative stress to dopaminergic neuron degeneration in PD. Increased oxidative stress contributes to DNA damage, leading to dopaminergic neuron degeneration and the pathogenesis of PD (2). Postmortem samples of PD have shown increased DNA oxidative damage selectively in dopaminergic neurons of the SNpc, indicating the link between DNA oxidation and the loss of dopaminergic neurons in PD (2). The classical widely-used pharmacological and toxic agent to model PD is 1-methyl-4-phenyl-1,2,3,6-tetrahydropyridine (MPTP) or its toxic metabolite 1-methyl-4-phenylpyridinium $\left(\mathrm{MPP}^{+}\right)$, which cause the production of reactive oxygen species by inhibiting mitochondrial complex I, leading to DNA oxidative damage and subsequent neuronal death (3). These previous reports support the hypothesis that DNA damage-induced cell death is a mechanism involved in the pathogenesis of PD. Proliferating cell nuclear antigen (PCNA) is a well-known protein, which is involved in DNA repair in a wide range of pathological conditions, including oxidative stress-mediated damage of DNA by interacting with a number of enzymes and regulatory proteins (4-6). The PCNA-dependent repair of damaged DNA is crucial in preserving its integrity under oxidative conditions $(7,8)$. Currently, the importance of this neuroprotective strategy to prevent or reverse the degeneration of dopaminergic neurons has been emphasized in the treatment of PD, which relies on the effective inhibition of the pathogenesis in 
neurodegenerative process. $\alpha$-lipoic acid (ALA) is a naturally occurring dithiol compound, which is synthesized enzymatically in the mitochondria from octanoic acid and cysteine. Its protective activities have been reported in vivo and in vitro against a range of pathophysiological insults (9), including $\mathrm{MPP}^{+}$-induced toxicity in neuronal cells (10). ALA has been in common clinical use for several diseases associated with increased oxidative stress, and its administration in moderate doses has produced no evidence of serious side-effects (10-16). Several studies have shown that ALA exerts protective effects in in vivo and in vitro models of neurodegenerative diseases, including Alzheimer's disease (AD), macular degeneration and PD (17-19).

The present study was designed to investigate the effects of ALA on an $\mathrm{MPP}^{+}$-induced PD model and to examine the mechanisms underlying these actions. The results demonstrated that ALA effectively prevented $\mathrm{MPP}^{+}$-induced PC12 cell apoptosis, suggesting the neuroprotective role of ALA in the neurodegenerative condition. The protein expression of PCNA was significantly decreased by $\mathrm{MPP}^{+}$treatment, supporting the hypothesis that PCNA-dependent apoptotic pathway is one potential molecular mechanism involved in the neuronal death in PD. Of note, ALA markedly reversed the decreased expression of PCNA in the $\mathrm{MPP}^{+}$-induced PD model. The effects of ALA on the PCNA upstream regulator, p53, were also examined. P53 interacts with the PCNA promoter to regulate the production of this protein, and a higher concentration of wild-type p53 inhibits the PCNA promoter, which results in a decrease in the production of PCNA $(20,21)$. ALA treatment markedly reduced the expression levels of p53, however, the expression of PCNA was upregulated. Together, these results confirmed that ALA upregulated the protective expression of protective PCNA and provided neuroprotection against the $\mathrm{MPP}^{+}$-induced neurotoxicity via the p53 pathway.

\section{Materials and methods}

Drugs and chemicals. All reagents and chemicals were purchased from Sigma-Aldrich; Merck Millipore (Darmstadt, Germany) unless stated otherwise.

Cell culture. The PC12 cells, obtained from the Cell Bank of the Chinese Academy of Sciences (Shanghai, China) were grown in high glucose Dulbecco's modifid Eagle's medium supplemented with $10 \%$ heat-inactivated fetal bovine serum, $4.00 \mathrm{mM}$ L-glutamine, $100 \mathrm{U} / \mathrm{ml}$ penicillin and $100 \mu \mathrm{g} / \mathrm{ml}$ streptomycin (Gibco; Thermo Fisher Scientific, Inc., Waltham, MA, USA). The cells, seeded at a density of 30,000 cells $/ \mathrm{cm}^{2}$, were plated onto $75-\mathrm{cm}$ tissue culture flasks and incubated in a humidified $5 \% \mathrm{CO}_{2}$ atmosphere at $37^{\circ} \mathrm{C}$. The cell monolayers were passaged on reaching $80-90 \%$ confluence, and passages 10-20 were used in the subsequent experiments.

Modified 3-(4,5-dimethylthiazol-2-yl)-2,5-diphenyl-tetrazolium bromide (MTT) assay. Cell viability was measured using an MTT colorimetric assay. MTT is readily taken up into cells, and is then reduced, predominantly by mitochondrial enzymes, to form blue formazan crystals, which are impermeable to cell membranes and are trapped in living cells. The PC12 cells were plated at the density of 30,000 cells $/ \mathrm{cm}^{2}$ in 96-well plates and incubated for $24 \mathrm{~h}$ at $37^{\circ} \mathrm{C}$ in a humidified $5 \% \mathrm{CO}_{2}$ incubator. To assess the toxicity of $\mathrm{MPP}^{+}$towards the PC12 cells, the cells were exposed to different doses $(0.5,1$ and $2 \mathrm{mM}$ ) of $\mathrm{MPP}^{+}$and incubated for $48 \mathrm{~h}$ at $37^{\circ} \mathrm{C}$. To assess the neuroprotective effects of ALA on $\mathrm{MPP}^{+}$-induced toxicity in the PC12 cells, the cells were pre-treated with $0.01 \mu \mathrm{M}$ ALA for $1 \mathrm{~h}$, and then exposed to $1 \mathrm{mM} \mathrm{MPP}^{+}$for $48 \mathrm{~h}$ at $37^{\circ} \mathrm{C}$, which were previously reported to be optimal conditions leading to significant protective effects (22). Following treatments, MTT solution $(5 \mathrm{mg} / \mathrm{ml})$ was added to each well, and the formed formazan crystals were dissolved in dimethyl sulfoxide. The absorbance of the colored solution was measured at $570 \mathrm{~nm}$ using a microplate reader (BioTek, Epoch, USA). The results are expressed as the percentage of the absorbance measured in control culture wells. The experiment was repeated three times.

Lactate dehydrogenase ( $L D H)$ cytotoxicity assay. Cell injury was further confirmed by measuring the activity of $\mathrm{LDH}$, which is expressed in all mammalian cells and is released from damaged cells into the culture medium. The activity of the released LDH in the culture supernatant was measured using LDH-Cytotoxicity Assay kits (BioVision Research Products, Mountain View, CA, USA) according to the manufacturer's protocol. Briefly, the PC12 cells were plated at a concentration of 30,000 cells $/ \mathrm{cm}^{2}$ for $24 \mathrm{~h}$ at $37^{\circ} \mathrm{C}$ in a humidified $5 \% \mathrm{CO}_{2}$ incubator, followed by treatment with $0.01 \mu \mathrm{M}$ ALA prior to the addition of $1 \mathrm{mM} \mathrm{MPP}^{+}$ for $1 \mathrm{~h}$. Following treatment, the cells were centrifuged at $5,000 \mathrm{x} \mathrm{g}$ for $10 \mathrm{~min}$ at $4^{\circ} \mathrm{C}$, and $50 \mu \mathrm{l}$ of the resulting supernatant was transferred into a separate 96 -well plate. A $100 \mu \mathrm{l}$ volume of the LDH reaction mixture was added to each well. Following incubation for $30 \mathrm{~min}$ at room temperature, the $\mathrm{LDH}$ activity was quantified as absorbance values at $490 \mathrm{~nm}$ using a multiwell spectrometer (BD Biosciences, San Diego, CA, USA). The data are expressed as a percentage of the fluorescence values in the untreated control.

Morphological observation of nuclear change. Apoptosis is a major type of cell death, characterized by a series of nuclear morphological changes, including reduced nuclear size, chromatin condensation, intense fluorescence and nuclear fragmentation. These changes can be detected by Hoechst 33258 staining, which is used for the quantification of apoptotic cells. Briefly, following treatment, the cells were washed with phosphate-buffered saline three times, and the cells were stained with $10 \mu \mathrm{g} / \mathrm{ml}$ Hoechst 33258 for $10 \mathrm{~min}$ at room temperature in the dark. Subsequently, the numbers of apoptotic cells were randomly counted under a fluorescence microscope (IX71; Olympus, Tokyo, Japan). The number of apoptotic cells is expressed as a percentage of the total cells counted.

Western blot analysis. Following treatment, the PC12 cells were collected and lysed with cell lysis solution containing $4 \%$ sodium dodecyl sulfate, $2 \mathrm{mM}$ EDTA and $50 \mathrm{mM}$ Tris-HCl ( $\mathrm{pH}$ 6.8). Protein concentration was determined using the Bradford method (GE Healthcare Life Sciences, Chalfont, UK). Equal quantities of protein $(40 \mu \mathrm{g})$ were separated by $12 \%$ polyacrylamide gel electrophoresis and 


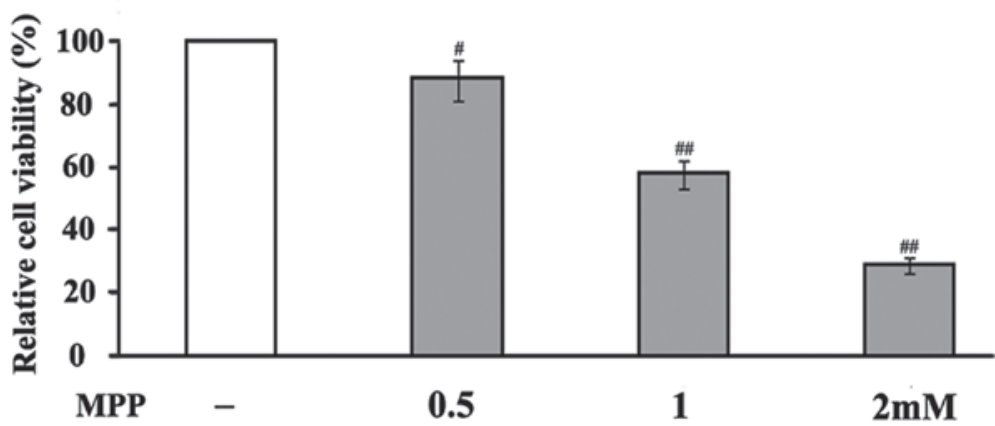

Figure 1. $\mathrm{MPP}^{+}$reduces the viability of PC12 cells. PC12 cells were treated with the indicated concentrations of MPP ${ }^{+}$for 48 h. The cell viability was determined using a 3-(4,5-dimethylthiazol-2-yl)-2,5-diphenyl-tetrazolium bromide assay. Data are presented as the mean \pm standard error of the mean of three independent experiments performed six times. ${ }^{~} \mathrm{P}<0.05$ and ${ }^{\# \#} \mathrm{P}<0.01$, vs. control. $\mathrm{MPP}^{+}, 1-$ methyl-4-phenylpyridinium.

transferred onto PVDF membranes (Amersham Biosciences, Upsalla, Sweden). The membranes were then incubated in Tris-buffered saline/Tween buffer supplemented with 5\% fat-free milk for $1 \mathrm{~h}$ to block nonspecific binding. Western blot analysis was performed using rabbit anti-PCNA $(1: 1,000$; cat. no. 610664; BD Biosciences) and anti-P53 (1:1,000; cat. no. 554157; BD Biosciences) overnight at $4^{\circ} \mathrm{C}$, and horseradish peroxidase-conjugated anti-rabbit antibodies (1:1,000; cat. no. R-21455; Thermo Fisher Scientific, Inc.) were used as the secondary antibodies and incubated at room temperature for $2 \mathrm{~h}$. The blots were analyzed using an enhanced chemiluminescence system (GE Healthcare Life Sciences).

Statistical analysis. Data are expressed as the mean \pm standard error of the mean. Statistical analysis was performed using one-way analysis of variance, followed by Dunnett's multiple-comparisons test. Analyses were performed using SPSS version 15.0 (SPSS, Inc., Chicago, IL, USA). P<0.05 was considered to indicate a statistically significant difference between mean values were.

\section{Results}

Neuroprotective ALA reduces $\mathrm{MPP}^{+}$-induced toxicity in neuronal cells. In an attempt to investigate the toxicity of $\mathrm{MPP}^{+}$ in PC12 cells, the cells were exposed to different doses $(0.5$, 1 and $2 \mathrm{mM}$ ) of $\mathrm{MPP}^{+}$. $\mathrm{MPP}^{+}$treatment significantly reduced the viability of the $\mathrm{PC} 12$ cells in a concentration-dependent manner (Fig. 1). After $48 \mathrm{~h}$ treatment, $0.5 \mathrm{mM} \mathrm{MPP}{ }^{+}$reduced cell viability to $88 \%$ compared to that of untreated cells, whereas 1 and $2 \mathrm{mM} \mathrm{MPP}{ }^{+}$decreased cell viability to 58 and $29 \%$, respectively. Based on these results, a concentration of $1 \mathrm{mM} \mathrm{MPP}{ }^{+}$was used in the following experiments to examine the neuroprotective effects of ALA on MPP ${ }^{+}$-induced toxicity in PC12 cells. The measurements revealed that the addition of $0.01 \mu \mathrm{M}$ ALA to the cells significantly improved the viability of the PC12 cells to $77 \%$ (Fig. 2A), showing the protective action of ALA in $\mathrm{MPP}^{+}$-induced neuron damage. The neuroprotective role of ALA was further confirmed using an LDH assay, which showed that, in the same conditions, ALA significantly reduced the activity of $\mathrm{LDH}$ induced by $\mathrm{MPP}^{+}$treatment in the PC12 cells. When the PC12 cells were treated with $1 \mathrm{mM} \mathrm{MPP}^{+}$for $48 \mathrm{~h}$, the activity of LDH was significantly increased, however $0.01 \mu \mathrm{M}$ ALA significantly reduced $\mathrm{MPP}^{+}$-induced $\mathrm{LDH}$ activity. ALA did not appear to affect the basal activity of LDH (Fig. 2B).

ALA reduces $M P P^{+}$-induced apoptosis in PC12 cells. To determine whether ALA prevents $\mathrm{MPP}^{+}$-induced apoptosis in PC12 cells, Hoechst 33258 staining assays were performed. Apoptosis characterized by a series of distinct nuclear morphological changes can be detected using Hoechst 33342 staining, a compound that binds nucleic acids. The administration of ALA alone did not induce changes in the number of apoptotic cells. The administration of $\mathrm{MPP}^{+}$significantly increased the number of apoptotic cells to $61 \%$, compared with the cells in the control group, whereas in the cells pre-treated with $0.01 \mu \mathrm{M}$ ALA, the proportion of apoptotic cells induced by $\mathrm{MPP}^{+}$treatment significantly reduced to $33 \%$ (Fig. 3), confirming the anti-apoptotic activities of ALA against the neurotoxicity of $\mathrm{MPP}^{+}$in the neuronal cells.

Neuroprotective ALA increases production of PCNA in $M P P^{+}$-treated PC12 cells. To investigate the mechanism underlying the neuroprotective activity of ALA, the present study investigated whether ALA had an effect on the expression of PCNA in the $\mathrm{MPP}^{+}$-induced PD model. Following treatment, the cells extracts were prepared, and western blot analyses were performed on the homogenates to examine the effect of ALA on the expression of PCNA. Consistent with our previous studies (data not shown), $\mathrm{MPP}^{+}$treatment significantly reduced the expression of PCNA in the PC12 cells, confirming the involvement of this protein in dopaminergic neuron loss in neurodegenerative conditions (6). Notably, ALA markedly increased the expression of PCNA altered by $\mathrm{MPP}^{+}$ treatment in the PC12 cells. When the PC12 cells were treated with $1 \mathrm{mM} \mathrm{MPP}{ }^{+}$for $48 \mathrm{~h}$, the protein expression of PCNA was markedly decreased, whereas $0.01 \mu \mathrm{M}$ ALA significantly increased the expression levels of PCNA in the $\mathrm{MPP}^{+}$-induced PC12 cells. ALA did not affect the basal expression of PCNA (Fig. 4). These results suggested that the PCNA protein was involved in dopaminergic neuron degeneration, and ALA exerted its neuroprotive action against the $\mathrm{MPP}^{+}$neurotoxicity in the dopaminergic neurons, at least in part, via modulating the production of PCNA.

$A L A$ represses the expression of $p 53$ induced by $M P P^{+}$in PC12 cells. In order to investigate the mechanism by which 
A

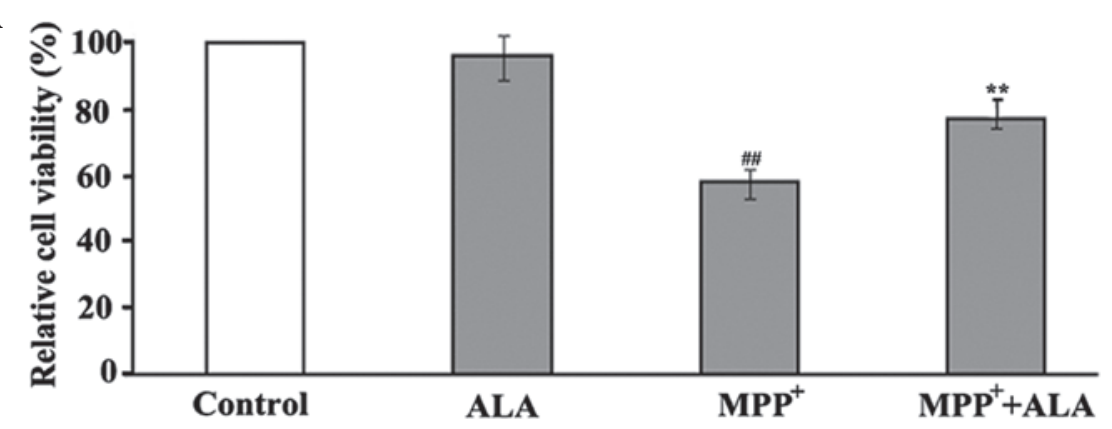

B

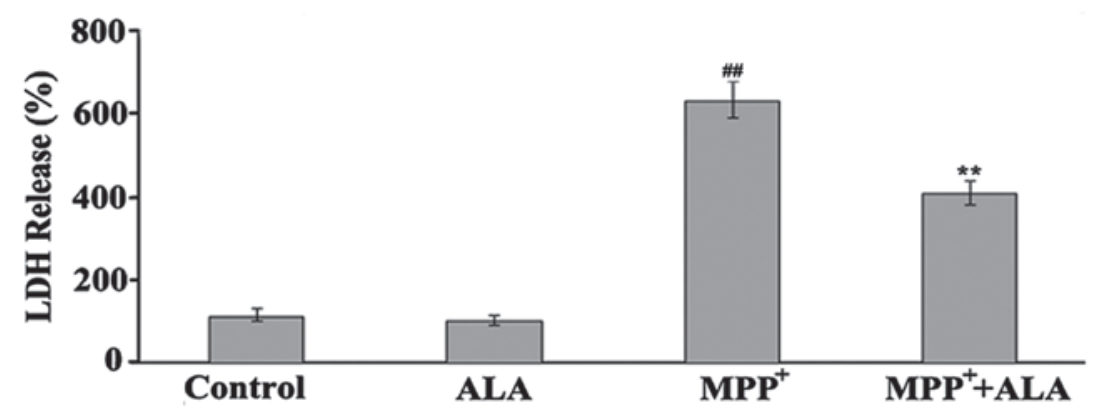

Figure 2. ALA attenuates the neurotoxicity of $\mathrm{MPP}^{+}$in $\mathrm{PC} 12$ cells. PC12 cells were pre-treated with $0.01 \mu \mathrm{M}$ ALA for $1 \mathrm{~h}$, and then exposed to $1 \mathrm{mM}$ MPP for $48 \mathrm{~h}$. (A) Cell viability was determined using a 3-(4,5-dimethylthiazol-2-yl)-2,5-diphenyl-tetrazolium bromide assay. (B) Cell injury was measured using an LDH assay. Data are presented as the mean \pm standard error of the mean. ${ }^{\# \#} \mathrm{P}<0.01$, vs. control; ${ }^{* *} \mathrm{P}<0.01, \mathrm{vs}$. MPP ${ }^{+}$treatment. ALA, $\alpha-1$ ipoic acid; $\mathrm{MPP}{ }^{+}$, 1-methyl-4-phenylpyridinium; LDH, lactate dehydrogenase.

A

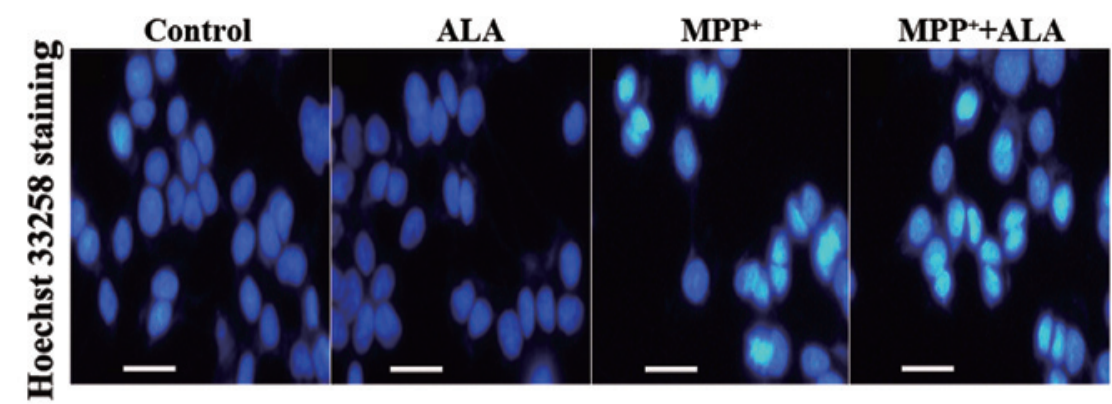

B

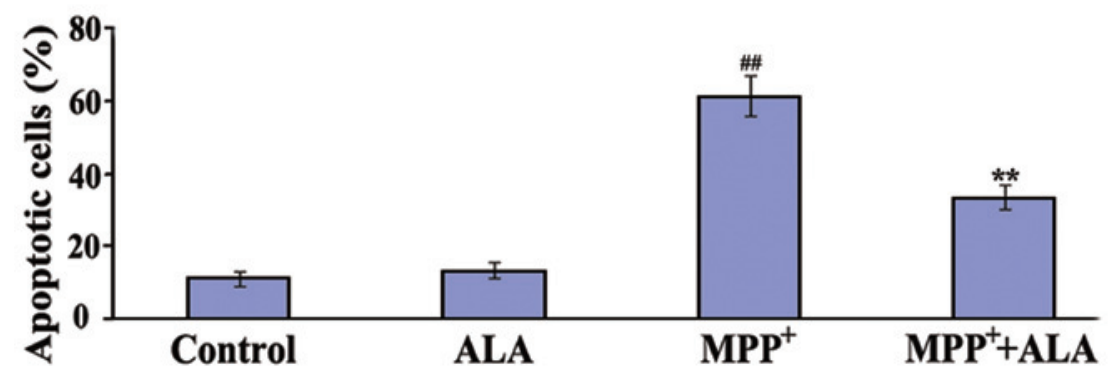

Figure 3. Effects of ALA on $\mathrm{MPP}^{+}$-induced neuronal cell apoptosis, analyzed using a Hoechst 33258 staining assay. (A) Hoechst 33258 staining. Scale bar, $20 \mu \mathrm{m}$. (B) Histogram presenting apoptotic cells as a percentage of the total cells. Data are presented as the mean \pm standard error of the mean ( $=3$ ). ${ }^{\#} \mathrm{P}<0.01$, vs. control; ${ }^{* *} \mathrm{P}<0.01$, vs. $\mathrm{MPP}^{+}$treatment. ALA, $\alpha$-lipoic acid; $\mathrm{MPP}^{+}, 1$-methyl-4-phenylpyridinium.

ALA repressed the expression of PCNA in the MPP+-treated PC12 cells, the present study examined the effects of ALA on the PCNA upstream regulator, p53. P53 interacts with the PCNA promoter to regulate the production of this protein, and a higher concentration of wild-type p53 inhibits the PCNA promoter, resulting in a decrease in the production of PCNA $(20,21)$. The role of the p53 protein in the pathogenesis of several neurodegenerative disorders, including PD, has been well documented $(22,23)$. The results of the present study revealed that the administration of $\mathrm{MPP}^{+}$caused a significant upregulation of the expression of $\mathrm{p} 53$ in $\mathrm{PC} 12$ cells. This expression pattern was in contrast to that of PCNA, as ALA treatment markedly reduced the expression levels of p53 induced by $\mathrm{MPP}^{+}$, but upregulated the expression of PCNA (Fig. 5). These results indicated that the mechanism by which ALA increased the expression of PCNA in the $\mathrm{MPP}^{+}$-treated 

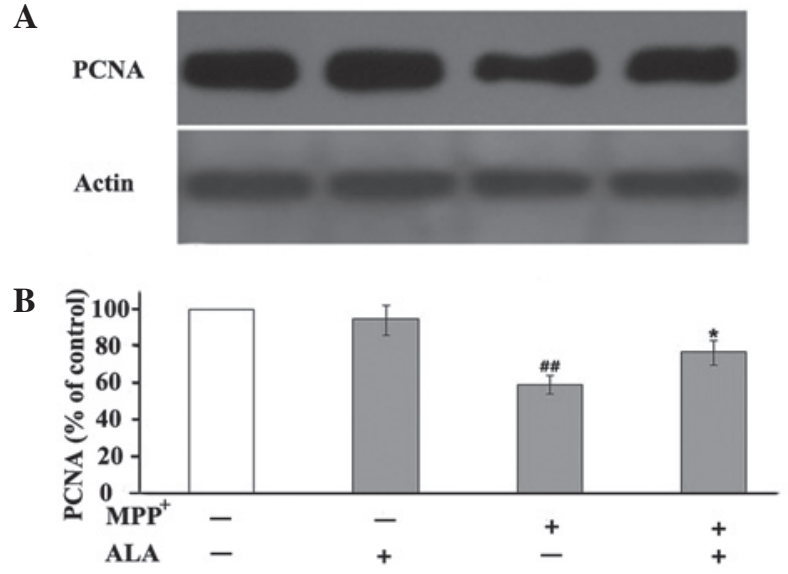

Figure 4. Effects of ALA on expression levels of PCNA in $\mathrm{MPP}^{+}$-induced PC12 cells. PC12 cells either remained untreated, or were treated with $1 \mathrm{mM}$ $\mathrm{MPP}^{+}$with or without $0.01 \mu \mathrm{M}$ ALA. (A) Protein expression levels of PCNA were determined using western blot analysis and actin levels were measured as a loading control. (B) Histograms of the percentage of PCNA content relative to the content of the control. Data are presented as the mean \pm standard error of the mean $(n=3) .{ }^{\# \#} \mathrm{P}<0.01$, vs. control; ${ }^{*} \mathrm{P}<0.05$, vs. $\mathrm{MPP}+$ treatment. ALA, $\alpha$-lipoic acid; MPP+ ${ }^{+}$1-methyl-4-phenylpyridinium; PCNA, proliferating cell nuclear antigen.

neuronal cells was associated with repression of the induction of $\mathrm{p} 53$.

\section{Discussion}

The present study demonstrated for the fist time, to the best of our knowledge, that ALA exerts its neuroprotective action mediated by upregulating the protein expression of PCNA via the p53 pathway in a cellular model of PD.

$\mathrm{PD}$ is a movement disorder, which is characterized by the gradually progressive and selective degeneration of dopaminergic neurons in the SNpc (24). The pathogenesis of PD remains to be fully elucidated, however, multiple studies have linked oxidative stress to dopaminergic neuron degeneration. Cell survival is dependent on DNA integrity. Under physical and pathological conditions, DNA is frequently subjected to damage by endogenous and environmental toxic agents, particularly in the SNpc, which results from oxidative stress due to its high levels of lipids, iron and dopamine metabolism (25). Increased oxidative stress causes oxidative DNA damage, which subsequently leads to dopaminergic neuron degeneration and the pathogenesis of PD. Postmortem samples of PD have shown increased DNA oxidative damage selectively in dopaminergic neurons of the SNpc, indicating the link between DNA oxidation and the loss of dopaminergic neurons (2). The association between DNA damage-induced cell death and the neurodegenerative process of PD is also supported by the presence of oxidized DNA in the brain tissues of mice treated with MPTP and other neuronal toxins, inducing a PD-like pathology (3). To counteract damage, repair mechanisms for DNA are required to preserve its integrity, particularly for dopaminergic neurons, which are more prone to oxidative damage (26-30). PCNA is a well-known protein, which is involved in DNA repair in a wide range of pathological conditions by interacting with a number of enzymes and regulatory proteins $(4,5)$. The PCNA-dependent
A P53

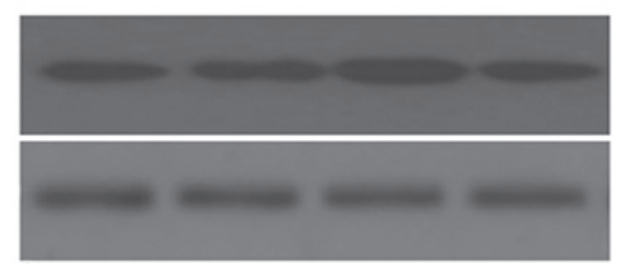

B

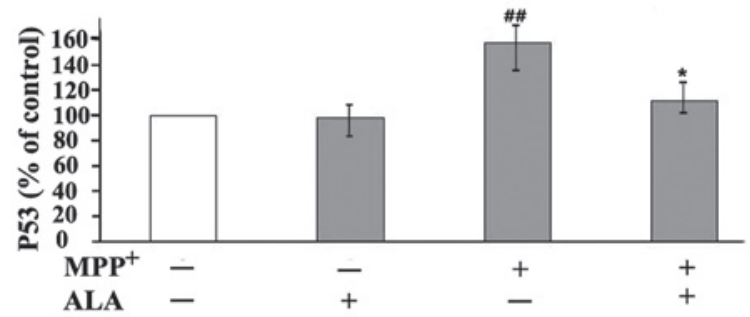

Figure 5. Effects of ALA on the expression of p53 in $\mathrm{MPP}^{+}$-induced $\mathrm{PC} 12$ cells. PC12 cells either remained untreated, or were treated with $1 \mathrm{mM} \mathrm{MPP}$ with or without $0.01 \mu \mathrm{M}$ ALA. (A) Expression levels of p53 were determined using western blot analysis and actin levels were measured as a loading control. (B) Histograms of the percentage of p53 content relative to the content of the control. Data are presented as the mean \pm standard error of the mean ( $\mathrm{n}=3$ ). ${ }^{\# \#} \mathrm{P}<0.01$, vs. control; ${ }^{*} \mathrm{P}<0.05$, vs. MPP+ treatment. ALA, $\alpha$-lipoic acid; $\mathrm{MPP}^{+}, 1-m e t h y l-4-p h e n y l p y r i d i n i u m$.

repair of DNA damage is crucial in preserving the integrity of DNA under oxidative conditions $(7,8)$. Our previous in vitro investigation of the mechanism underlying the degeneration of dopaminergic neurons in $\mathrm{MPP}^{+}$-induced $\mathrm{PC} 12$ cells indicated that PCNA was involved in DNA damage-induced cell death in oxidative conditions (data not shown) (6). In the present study, $\mathrm{MPP}^{+}$treatment significantly reduced the expression of PCNA in the PC12 neuronal cells, and increased the number of apoptotic cells, indicating that a PCNA-dependent apoptotic pathway is one potential molecular mechanism involved in neuronal death in the pathogenesis of PD. Thus, effects of PCNA in reversing degeneration may be beneficial in neurodegenerative conditions.

ALA is a naturally occurring dithiol compound, synthesized enzymatically in mitochondria from octanoic acid and cysteine. In addition to its function as an essential cofactor for mitochondrial bioenergetic enzymes in the production of energy, ALA is involved in a set of biochemical activities with potential pharmacotherapeutic value against a range of pathophysiological insults $(9,31)$. Several studies have shown that exogenous ALA can readily cross the blood-brain barrier $(32,33)$. Notably, the neuroprotective actions of ALA have been reported in in vivo and in vitro models of neurodegenerative diseases, including $\mathrm{AD}$, macular degeneration and PD (17-19). The present study showed that the addition of ALA markedly increased the expression levels of PCNA in the $\mathrm{MPP}^{+}$-induced $\mathrm{PC} 12$ cells and reduced cell apoptosis, suggesting that ALA upregulated the expression of the protective PCNA protein, in addition to providing neuroprotection against the $\mathrm{MPP}^{+}$-induced neurotoxicity.

The mechanisms underlying the effect of ALA on the expression of PCNA remain to be fully elucidated. It may be associated with its ability to regulate the p53 protein, as P53 is the most well-characterized mechanism for modulating the production of PCNA through the binding of its promoter $(20,21)$. P53 was originally identified as a tumor suppressor gene, and has been 
considered to be a key contributor in neuronal cell death and dopaminergic neuron degeneration $(34,35)$. The pharmacologic inhibition of p53 has been shown to preserve dopamine neurons against the neurotoxic effects of MPTP and other neuronal toxins that induce PD-like pathology in in vivo and in vitro models of PD (23,36-39). The classical trigger for $\mathrm{p} 53$ activation is oxidative stress, and p53-dependent apoptosis in neuronal cells is predominantly mediated by DNA damage (34,35). P53 is an upstream inducer of PCNA, and a higher concentration of wild-type p53 inhibits the PCNA promoter and reduces the production of PCNA $(20,21)$. The results of the present study showed that $\mathrm{MPP}^{+}$significantly increased the expression of P53 in the dopaminergic neuronal cells and reduced the cell viability, indicating that P53 is a contributor in the pathogenesis of PD. The decrease in the expression of PCNA was also observed in the $\mathrm{MPP}^{+}$-induced PD model, and this expression pattern was in contrast to that of the expression of P53, suggesting a correlation between P53 and the expression of PCNA in oxidative conditions. Furthermore, LA efficiently reduced the expression of p53 induced by $\mathrm{MPP}^{+}$in the PC12 cells, and upregulated the expression of PCNA. These results suggested that ALA protected the dopaminergic neurons against $\mathrm{MPP}^{+}$-induced neurotoxicity through its ability to upregulate the DNA repair protein, PCNA, via the P53 pathway.

The present study provided the first evidence, to the best of our knowledge, that neuroprotective ALA exerts anti-apoptotic effects on neuronal cells by upregulating the expression of PCNA via repression of p53 in an $\mathrm{MPP}^{+}$-induced cellular model of PD. Previous studies have shown that ALA has anti-inflmmatory and anti-oxidative properties in a range of cell types and tissues (40-43), which may be beneficial in neurodegenerative conditions. Preclinical and clinical data have indicated that ALA is bioavailable and safe in moderate doses (8). Further investigations are required to fully elucidate the mechanisms responsible for the protective effects of ALA in neurodegenerative conditions, which may provide a potential effective neuroprotection strategy for the treatment of PD by targeting DNA damage-mediated neuronal degeneration.

\section{References}

1. de Lau LM and Breteler MM: Epidemiology of Parkinson's disease. Lancet Neurol 5: 525-535, 2006.

2. Alam ZI, Jenner A, Daniel SE, Lees AJ, Cairns N, Marsden CD, Jenner P and Halliwell B: Oxidative DNA damage in the parkinsonian brain: An apparent selective increase in 8-hydroxyguanine levels in substantia nigra. J Neurochem 69: 1196-1203, 1997.

3. Mandir AS, Przedborski S, Jackson-Lewis V, Wang ZQ, Simbulan-Rosenthal CM, Smulson ME, Hoffman BE, Guastella DB, Dawson VL and Dawson TM: Poly (ADP-ribose) polymerase activation mediates 1-methyl-4-phenyl-1, 2,3,6-tetrahydropyridine (MPTP)-induced parkinsonism. Proc Natl Acad Sci USA 96: 5774-5779, 1999.

4. Moldovan GL, Pfander B and Jentsch S: PCNA, the maestro of the replication fork. Cell 129: 665-679, 2007.

5. Mailand N, Gibbs-Seymour I and Bekker-Jensen S: Regulation of PCNA-protein interactions for genome stability. Nat Rev Mol Cell Biol 14: 269-282, 2013.

6. Li DW, Li GR, Zhang BL, Feng JJ and Zhao H: Damage to dopaminergic neurons is mediated by proliferating cell nuclear antigen through the p53 pathway under conditions of oxidative stress in a cell model of Parkinson's disease. Int J Mol Med 37: 429-435, 2016.

7. Burkovics P, Hajdú I, Szukacsov V, Unk I and Haracska L: Role of PCNA-dependent stimulation of 3'-phosphodiesterase and 3'-5' exonuclease activities of human Ape2 in repair of oxidative DNA damage. Nucleic Acids Res 37: 4247-4255, 2009.
8. Amoroso A, Concia L, Maggio C, Raynaud C, Bergounioux C, Crespan E, Cella R and Maga G: Oxidative DNA damage bypass in Arabidopsis thaliana requires DNA polymerase $\lambda$ and proliferating cell nuclear antigen 2. Plant Cell 23: 806-822, 2011.

9. Shay KP, Moreau RF, Smith EJ, Smith AR and Hagen TM: Alpha-lipoic acid as a dietary supplement: Molecular mechanisms and therapeutic potential. Biochim Biophys Acta 1790: 1149-1160, 2009

10. Wollin SD and Jones PJ: Alpha-lipoic acid and cardiovascular disease. J Nutr 133: 3327-3330, 2003.

11. McNeilly AM, Davison GW, Murphy MH, Nadeem N, Trinick T, Duly E, Novials A and McEneny J: Effect of $\alpha$-lipoic acid and exercise training on cardiovascular disease risk in obesity with impaired glucose tolerance. Lipids Health Dis 10: 217, 2011.

12. Stanković MN, Mladenović D, Ninković M, Ethuričić I, Sobajić S, Jorgačević B, de Luka S, Vukicevic RJ and Radosavljević TS: The effects of $\alpha$-lipoic acid on liver oxidative stress and free fatty acid composition in methionine-choline deficient diet-induced NAFLD. J Med Food 17: 254-261, 2014.

13. Hatami S, Zavareh S, Salehnia M, Lashkarbolouki T, Ghorbanian MT and Karimi I: Total oxidative status of mouse vitrified pre-antral follicles with pre-treatment of alpha lipoic acid. Iran Biomed J 18: 181-188, 2014.

14. Showkat A, Bastnagel WR and Hudson JQ: Effect of $\alpha$-lipoic acid on oxidative stress in end-stage renal disease patients receiving intravenous iron. ISRN Nephrol 2014: 634515, 2014.

15. Ziegler D, Hanefeld M, Ruhnau KJ, Meissner HP, Lobisch M, Schütte $\mathrm{K}$ and Gries FA: Treatment of symptomatic diabetic peripheral neuropathy with the anti-oxidant alpha-lipoic acid. A 3-week multicentre randomized controlled trial (ALADIN Study). Diabetologia 38: 1425-1433, 1995.

16. Ziegler D, Hanefeld M, Ruhnau KJ, Hasche H, Lobisch M, Schütte K, Kerum G and Malessa R: Treatment of symptomatic diabetic polyneuropathy with the antioxidant alpha-lipoic acid: A 7-month multicenter randomized controlled trial (ALADIN III Study). ALADIN III study group. Alpha-lipoic acid in diabetic neuropathy. Diabetes Care 22: 1296-1301, 1999.

17. Sancheti H, Kanamori K, Patil I, Diaz Brinton R, Ross BD and Cadenas E: Reversal of metabolic deficits by lipoic acid in a triple transgenic mouse model of Alzheimer's disease: A 13C NMR study. J Cereb Blood Flow Metab 34: 288-296, 2014.

18. Mansoor S, Gupta N, Luczy-Bachman G, Limb GA, Kuppermann BD and Kenney MC: Protective effects of lipoic acid on chrysene-induced toxicity on Müller cells in vitro. Mol Vis 19: 25-38, 2013.

19. Li DW, Li GR, Lu Y, Liu ZQ, Chang M, Yao M, Cheng W and $\mathrm{Hu}$ LS: $\alpha$-lipoic acid protects dopaminergic neurons against MPP+-induced apoptosis by attenuating reactive oxygen species formation. Int J Mol Med 32: 108-114, 2013.

20. Morris GF, Bischoff JR and Mathews MB: Transcriptional activation of the human proliferating-cell nuclear antigen promoter by p53. Proc Natl Acad Sci USA 93: 895-899, 1996.

21. Shivakumar CV, Brown DR, Deb S and Deb SP: Wild-type human p53 transactivates the human proliferating cell nuclear antigen promoter. Mol Cell Biol 15: 6785-6793, 1995.

22. Martin LJ: p53 is abnormally elevated and active in the CNS of patients with amyotrophic lateral sclerosis. Neurobiol Dis 7 : 613-622, 2000.

23. Duan W, Zhu X, Ladenheim B, Yu QS, Guo Z, Oyler J, Cutler RG, Cadet JL, Greig NH and Mattson MP: p53 inhibitors preserve dopamine neurons and motor function in experimental parkinsonism. Ann Neurol 52: 597-606, 2002.

24. Forno LS: Neuropathology of Parkinson's disease. J Neuropathol Exp Neurol 55: 259-272, 1996.

25. Dias V, Junn E and Mouradian MM: The role of oxidative stress in Parkinson's disease. J Parkinsons Dis 3: 461-491, 2013.

26. Montine KS, Quinn JF, Zhang J, Fessel JP, Roberts LJ II, Morrow JD and Montine TJ: Isoprostanes and related products of lipid peroxidation in neurodegenerative diseases. Chem Phys Lipids 128: 117-124, 2004.

27. Sadrzadeh SM and Saffari Y: Iron and brain disorders. Am J Clin Pathol 121 (Suppl): S64-S70, 2004.

28. Jomova $\mathrm{K}$ and Valko $\mathrm{M}$ : Advances in metal-induced oxidative stress and human disease. Toxicology 283: 65-87, 2011.

29. Nagatsu $T$ and Sawada M: Molecular mechanism of the relation of monoamine oxidase B and its inhibitors to Parkinson's disease: Possible implications of glial cells. J Neural Transm Suppl: 53-65, 2006.

30. Núñez MT, Urrutia P, Mena N, Aguirre P, Tapia V and Salazar J: Iron toxicity in neurodegeneration. Biometals 25: 761-776, 2012. 
31. Goraca A, Huk-Kolega H, Piechota A, Kleniewska P, Ciejka E and Skibska B: Lipoic acid-biological activity and therapeutic potential. Pharmacol Rep 63: 849-858, 2011.

32. Panigrahi M, Sadguna Y, Shivakumar BR, Kolluri SV, Roy S, Packer L and Ravindranath V: Alpha-Lipoic acid protects against reperfusion injury following cerebral ischemia in rats. Brain Res 717: 184-188, 1996.

33. Arivazhagan P, Shila S, Kumaran S and Panneerselvam C: Effect of DL-alpha-lipoic acid on the status of lipid peroxidation and antioxidant enzymes in various brain regions of aged rats. Exp Gerontol 37: 803-811, 2002.

34. Chipuk JE and Green DR: Dissecting p53-dependent apoptosis Cell Death Differ 13: 994-1002, 2006.

35. Culmsee $\mathrm{C}$ and Mattson MP: p53 in neuronal apoptosis. Biochem Biophys Res Commun 331: 761-777, 2005.

36. Mandir AS, Simbulan-Rosenthal CM, Poitras MF, Lumpkin JR Dawson VL, Smulson ME and Dawson TM: A novel in vivo post-translational modification of p53 by PARP-1 in MPTP-induced parkinsonism. J Neurochem 83: 186-192, 2002.

37. Nair VD: Activation of $\mathrm{p} 53$ signaling initiates apoptotic death in a cellular model of Parkinson's disease. Apoptosis 11: 955-966, 2006.
38. Biswas SC, Ryu E, Park C, Malagelada C and Greene LA: Puma and p53 play required roles in death evoked in a cellular model of Parkinson disease. Neurochem Res 30: 839-845, 2005.

39. Nakaso K, Yoshimoto Y, Yano H, Takeshima T and Nakashima K: p53-mediated mitochondrial dysfunction by proteasome inhibition in dopaminergic SH-SY5Y cells. Neurosci Lett 354: 213-216, 2004.

40. Busse E, Zimmer G, Schopohl B and Kornhuber B: Influence of alpha-lipoic acid on intracellular glutathione in vitro and in vivo. Arzneimittelforschung 42: 829-831, 1992.

41. Talebi A, Zavareh S, Kashani MH, Lashgarbluki T and Karimi I: The effect of alpha lipoic acid on the developmental competence of mouse isolated preantral follicles. J Assist Reprod Genet 29: 175-183, 2012.

42. Packer L, Witt EH and Tritschler HJ: Alpha-Lipoic acid as a biological antioxidant. Free Radic Biol Med 19: 227-250, 1995.

43. Packer L, Tritschler HJ and Wessel K: Neuroprotection by the metabolic antioxidant alpha-lipoic acid. Free Radic Biol Med 22: 359-378, 1997. 